Brit. J. Ophthal. (1960) 44, 406.

\title{
VITAMIN DEFICIENCIES IN RELATION TO THE EYE*
}

\author{
BY \\ MEKKI EL SHEIKH \\ Sudan
}

VitAMINS are essential constituents present in minute amounts in natural foods. If these constituents are removed or deficient such foods are unable to support nutrition and symptoms of deficiency or actual disease develop.

Although vitamins are unconnected with energy and protein supplies, yet they are necessary for complete normal metabolism. They are, however, not invariably present in the diet under all circumstances. Childhood and periods of growth, heavy work, childbirth, and lactation all demand the supply of more vitamins, and under these conditions signs of deficiency may be present, although the average intake is not altered.

The criteria for the fairly accurate diagnosis of vitamin deficiencies are evidence of deficiency, presence of signs and symptoms, and improvement on supplying the deficient vitamin.

It is easy to discover signs and symptoms of vitamin deficiencies, but it is not easy to tell that this or that vitamin is actually deficient in the diet of a certain individual, unless one is able to assess the exact daily intake of food, a process which is neither simple nor practical.

Another way of approach is the assessment of the vitamin content in the blood or the measurement of the course of dark adaptation which demonstrates a real deficiency of vitamin A (Adler, 1953). Both tests entail more or less tedious laboratory work which is not easy in a provincial hospital.

Response to the supply of the deficient vitamin or vitamins, on the other hand, is a simple reliable test, which I have used in my first series of 670 cases, which $I$ have seen and followed up as in-patients and out-patients in the central hospital at Wad Medani.

In my second series, consisting of 595 cases, mostly schoolchildren, seen during a survey in some of the Gezira villages, my diagnosis was based on definite clinical signs alone.

Vitamin deficiency is usually multiple and may at times be associated with general sub-nutrition and an unbalanced diet. It is customary to consider each vitamin with its specific manifestations separately, although there is really no sharp demarcation between one vitamin deficiency and the other. Xerophthalmia, for instance, is generally associated with rickets in cold climates. In Barlow's disease there is frequently co-existence of both scurvy and rickets in the same child. Avitaminosis-B is hardly ever seen in an isolated form. The whole symptomatology and clinical picture are so closely associated and interwoven that, at the best, one can say with certainty that the deficiency of one vitamin predominates (Sheldon, 1955; Davidson, 1956).

Vitamin A

Of all vitamins described so far, vitamin $\mathbf{A}$ is the most important as far as

* Received for publication May 22, 1959. 
ocular pathology is concerned. In fact ocular symptoms and signs dominate over all general manifestations of the vitamin deficiency, and are so characteristic that they are unlikely to be missed even by the novice.

It is interesting to note that, contrary to the general belief, most of the members of my series are children and not young adults and there are more females than males.

The three cardinal features (xerophthalmia, keratomalacia, and night blindness) were manifested in my two series totalling 1,265 cases in varying proportions. Keratomalacia was almost completely restricted to infants and very young children, most of them emaciated and marasmic, and all of them in the ulceration and perforation stages.

55 such cases $(4 \cdot 3$ per cent.) were seen in hospital during a period of 3 years; some of them died in hospital and, of the survivors, none had a residual sight of more than perception of light. It is very likely that in some of the patients in this series the deficiency disease did not result primarily from insufficient supply of vitamin A, but from defective absorption due to neglected gastro-intestinal derangement and other debilitating conditions. This opinion is based on their conditions at the time of coming to hospital and the history given by their parents.

Xerophthalmia with and without night blindness was seen in 409 cases (32.33 per cent.), the majority again being female children and young adults. Bitot's syndrome, comprising the characteristic triangular epithelial xerotic spots and defective vision at night, was present in various degrees of severity.

Epithelial xerosis of the whole bulbar conjunctiva, converting it into a lustreless dry insensitive sheet, was seen in 38 cases, and extension of the xerotic process to the cornea giving rise to epithelial corneal xerosis, partial and complete, was seen in 23 cases. Of the latter, nine cases, presented with complete mummification of both corneae (Fig. 1), and another patient (a girl

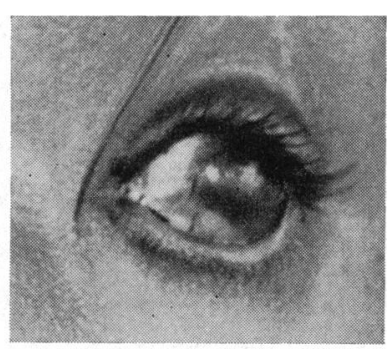

Fig. 1,-Marked conjunctivocorneal xerosis with complete mummification of the cornea. aged 14) showed a completely mummified left corneà and a densely vascularized right cornea (Fig. 2).

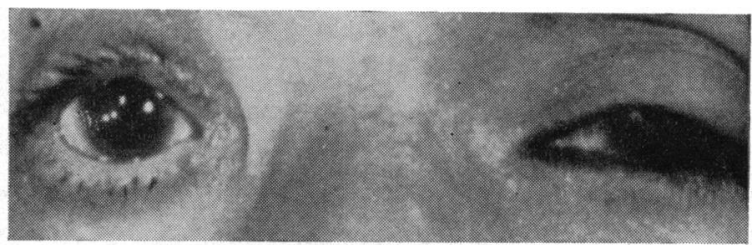

FIG. 2.-Advanced corneo-conjunctival xerosis of left eye with heavy vascularization of right cornea.

This I consider a good example of the multiple nature of the deficiency, because this patient responded favourably to treatment with vitamin B-complex which is blamed, with some validity, for the production of vascular keratitis (Trevor-Roper, 1955; Sorsby, 1951). 
In studying these cases I have considered and carefully eliminated causes other than deficiency, e.g. trachoma, injury, and ocular pemphigus. It is doubtful whether these conditions have anything to do with deficiencies, but it has been suggested that local disturbances of the supply of vitamin A to the conjunctiva may be a causal factor, although the light sense and the vitamin content of the blood may be normal.

How much truth there is in this statement I cannot tell, but I find it plausible for the following reason: it is known that vitamin A can be formed from its precursor, carotene; this occurs through the intestinal mucosa, but it has recently been found that such conversion is also possible in the sebaceous glands of the skin. It has further been suggested that one of the functions of the sebaceous glands of the skin may be the withdrawal of carotene from plasma and its conversion into vitamin A. Hence, if sebaceous secretion is disturbed in any way, too little vitamin A will be available for the skin and the deficiency signs such as dryness and hyperkeratosis may thus be accounted for.

The conjunctiva, like skin, has a rich supply of sebaceous glands. In fact, certain regions, such as the caruncle and transitional areas like the limbus, closely resemble skin. It is reasonable to suppose, therefore, that in traumatism and inflammatory conditions such as trachoma and ocular pemphigus, the sebum-secreting structures may be destroyed or disturbed by the resultant fibrotic process, and that this may lead to dryness and hyperkeratosis of the conjunctiva.

However, it is not intended to discuss such cases here, nor cases with other ocular manifestations such as certain forms of keratitis, especially those of a herpetic nature, kerato-conjunctivitis sicca, phlyctenular kerato-conjunctivitis, epithelial dystrophy, and retinitis pigmentosa which have been attributed to vitamin A deficiency (Town, 1951) without much evidence.

Whether vitamin A deficiency in the mother contributes to any degree to the production of congenital anomalies and malformations (Sorsby, 1948) still remains to be substantiated. However, the following instance, apart from being interesting, is decidedly relevant. A woman aged 35, presenting with severe signs and symptoms of vitamin A deficiency.(Fig. 3) had two children with anophthalmos and microphthalmos (Fig. 4).

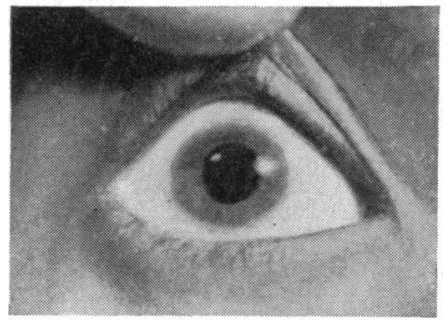

Fig. 3.-An example of conjunctivo-cornea xerosis with extreme skin manifestation approaching "goose skin".

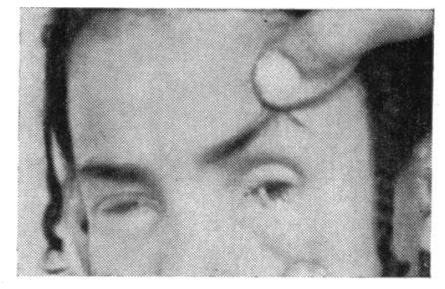

FIG. 4.-Congenital anophthalmos and microphthalmos. The patients' mother showed severe symptoms and signs of vitamin A deficiency. 
Developmental defects may arise at any time from conception to senility; it is obvious, therefore, that developmental and congenital anomalies are not synonymous. We generally speak of "congenital" defects of the eyes. This is justified only because we know that most of the common ocular anomalies start before birth, and that gross defects such as anophthalmos and congenital cystic eyes arise during the early organogenetic stage, while minor defects usually arise later in foetal life (Mann, 1949).

The causal genesis is not only legion, but controversial. Some of these anomalies are purely genetic in origin; others, although genetically determined, are environmentally produced. An environment may be nutritional. Examples exist in the literature (Adams and Maegraith, 1953) of hereditary facial bone deformity produced experimentally in rats, only if the mother is deficient in vitamin D. It is thought possible also (Sorsby, 1948) that some forms of zonular cataracts may belong to this category.

Data on the effect of nutritional defect or excess in man are at present lacking, and it remains to be authenticated by further research that vitamin deficiencies can be causal factors in producing congenital and developmental anomalies.

Night blindness without visible signs was manifested by 245 cases in the present series (19.37 per cent.). No investigations such as light sense and vitamin content of the blood were carried out; the only valid proofs I have were the good response, dramatic in some cases, to vitamin A therapy and the elimination of causes of night blindness other than vitamin A deficiency. Only 27 patients, all young adults, in whom no discoverable cause could be found for the symptom of night blindness, showed no improvement to vitamin A therapy. These cases can safely be considered as examples of physiological variations in light sense, not to mention psychic factors.

\section{Vitamin B}

Of ocular changes claimed to be due to avitaminosis $B_{1}$, mild keratoconjunctival lesions, together with symptoms such as smarting and photophobia, and visual disturbances including night blindness, were discovered among some of the schoolchildren in a survey of two elementary schools at Nuela (one of the Gezira irrigated-area villages).

Altogether, 595 cases were examined and at least 80 per cent. showed definite signs of multiple avitaminosis in varying degrees of severity.

27 cases of retrobulbar neuritis, with no discoverable cause and with signs and symptoms of $B_{1}$ avitaminosis, were discovered among adults coming to hospital during the same period. In all but one no fundus changes were seen and it was only through visual disturbances that the condition was suspected. Central and caeco-central scotomata of varying densities, in addition to peripheral constriction of the visual fields, were manifested by all cases. 
Response to treatment by vitamin $\mathrm{B}_{1}$ and $\mathrm{B}$-complex was disappointing in the majority of cases, probably because of the presence of other conditioning factors and because of the fact that they came at an irreversible stage.

However, only one case of recent origin, showing mild oedema of the posterior pole, macular pigmentation, and narrowing of the vessels, responded reasonably well to vitamin therapy with disappearance of the signs and improvement of the visual acuity and visual fields.

It is thought that, in conditions of deficiency of vitamin $B_{1}$, there is probably interference with the carbohydrate metabolism of the nerves and the central nervous tissue, and that this may be the cause of the polyneuritis and acute haemorrhagic lesions that form some of the cardinal symptoms of the deficiency of this vitamin. In support of this is the frequent association of avitaminosis $B_{1}$ and alcohol which is an established neuro-toxin and which impairs the absorption of this vitamin, not only by its damaging action on the mucosa of the alimentary canal, but also by its high caloric value as a food and, consequently, its augmenting effect on the relative deficiency by creating a greater need for the vitamin.

Nuclear ocular palsies of every type, resulting in irregular bilateral, ophthalmoplegias of varying degrees, are also attributed to avitaminosis- $B_{1}$. This has received ample confirmation, not only as being true, but also as being of a not uncommon occurrence (Duke-Elder, 1949; Sorsby, 1951; Trevor-Roper, 1955).

One interesting case is worth reporting:

A chronic alcoholic, 47 years old, had transient diplopia on looking to the left as his sole symptom. Examination revealed paresis of the left lateral rectus, the cause of which could not be traced. 3 months later, this patient returned with a true picture of sixth nerve paralysis and ptosis. Again no cause could be found and treatment by liberal doses of thiamine was tried. Shortly after this, the patient started to show signs of improvement; in about 3 months he became perfectly normal and his partial ophthalmoplegia disappeared completely.

Vitamin B-complex deficiency was much more prevalent in this survey, and its outstanding features were obvious in 304 cases ( 24 per cent.). Angular stomatitis, cheilosis, gingivitis, and glossitis were common features. Of the ocular symptoms and signs the commonest were blepharitis, kerato-conjunctivitis, itching and burning, photophobia, and vascular keratitis. The latter, rare as it was, responded remarkably well to riboflavin therapy. This may lend support to the suggestion that riboflavin deficiency is at least one factor in the production of corneal vascularization.

\section{Vitamin C}

Deficiency of this vitamin was not as common as that of the A and B groups, at least as far as ocular pathology is concerned. General signs, however, were of commoner occurrence. Frank scurvy of the infantile or the adult type was not discovered, but milder signs, such as scorbutic gingivitis, scorbutic buds, etc., were among the features frequently seen. There 


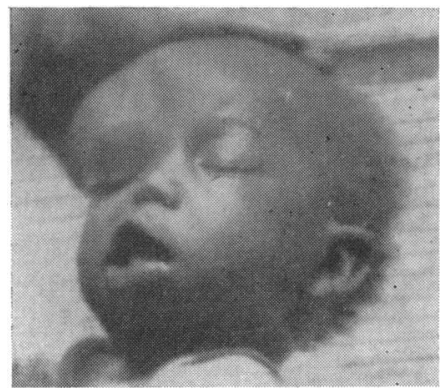

were 62 cases with ocular manifestations ( 5 per cent.), and among these the main features were conjunctival and orbital haemorrhage (Fig. 5).

FIG. 5.-A spontaneous orbital haemorrhage with other manifestations of vitamin $\mathrm{C}$ deficiency responding favourably to replacement therapy assisted by local injections of hyaluronidase.

The rarity of infantile scurvy may be due to the fact that practically all infants here are breast-fed; mother's milk is a rich source of vitamin C, provided, of course, that the mother is getting enough of it herself in her food.

In the hospital cases post-operative haemorrhages occurred only very occasionally. This is due partly to the preferential selection of healthier patients for operation, and partly to the pre-operative medication given to those who showed signs and symptoms suggestive of the deficiency. Rarer still were bleeding into the anterior chamber and retinal haemorrhages. Only five cases, with severe anaemia in addition, showed retinal haemorrhages and three others showed spontaneous hyphaema or oligaemia.

Response to treatment by a balanced diet and by administering ascorbic acid by injections for cases treated in hospital gave much better results than those obtained in the other groups of the series.

Vitamin D deficiency is not common here, and I have not come across a single case with ocular changes due to its deficiency.

\section{Discussion}

Almost as soon as the existence of vitamin A was established, its association with night blindness was suspected, and it was suggested by Parinaud (1881) that the poor dark adaptation characteristic of night blindness was due to a faulty production of visual purple which is essential for night vision. Since vitamin A forms an integral part of the visual purple molecule, it is easy to understand why the absence or deficiency of vitamin A should result in night blindness. In other words, night blindness due to vitamin A deficiency is curable, because it is caused by the inadequate production of visual purple in otherwise healthy rods, whereas simple congenital night blindness and the form that characterizes the early stages of retinitis pigmentosa are incurable because they are due to an abnormality of the rods themselves (Haessler, 1953).

Of the vitamin B-complex group, two members seem to be concerned with the metabolism of visual pigments, namely nicotinamide and riboflavin. In support of this is the experimental evidence that visual purple can be synthesized in vitro from a mixture of vitamin $A_{1}$, dehydrogenase (which contains nicotinamide), cozymase (which contains riboflavin), and protein 
from the retinal rods. Dehydrogenase, with cozymase acting as a co-enzyme, oxidizes the vitamin A to its aldehyde (retinene), which combines with protein to form visual purple.

If this applies to man as well-and in all probability it does-then the blame for night blindness should be put not on deficiency of vitamin A alone, but also on deficiency of the B-complex group.

The importance attached to riboflavin for maintaining corneal transparency also finds support from laboratory experiments only, and for this reason the absence of riboflavin is not accepted as a specific cause for corneal vascularization. Being an avascular structure, the cornea is devoid of any mechanism which increases its oxygen supply at need. Any condition which upsets its metabolism tends to evoke vascularization, as the extra requirement of oxygen cannot be made directly from air and ocular fluids. Further, cataract has been claimed to be produced experimentally in rats deficient in riboflavin (Sorsby, 1951), but there is no real evidence to support this in man, and the appearance of cataract, at any rate, has not been proved to be linked to riboflavin deficiency.

Regarding vitamin C, the role it plays in the oxidation-reduction system of the lens cannot be denied. The high concentration of vitamin $\mathrm{C}$ in the lens and aqueous humour gives plausibility to the suggestion that this substance is concerned in the lens metabolism. (Davson, 1949; Duke-Elder and Goldsmith, 1951; Adler, 1953). An argument for this is the disappearance of ascorbic acid and its ally (glutathione) from cataractous lenses, although cataract is not a symptom of scurvy and vitamin $C$ is not a treatment for cataract.

An important relevant factor among the 595 schoolchildren examined was anaemia, which may not only have added to the severity of the deficiency, but may also have constituted an important causal factor in the visual disturbances in some of the cases.

Lack of staff and adequate equipment, again, made it necessary to estimate haemoglobin percentages only. None of these boys and girls had a value above 80 per cent. and readings as low as 30 per cent. were not uncommon. An average of the haemoglobin content was 60 to 65 per cent. (Table I).

TABLE I

TOTAL NUMBER OF CASES EXAMINED, 556

\begin{tabular}{c|c|c}
\hline Haemoglobin Content (per cent.) & No. of Cases & Percentage \\
\hline $80-70$ & 168 & $30 \cdot 15$ \\
\hline $70-60$ & 246 & $44 \cdot 5$ \\
\hline $60-50$ & 84 & 15 \\
\hline $50-40$ & 12 & $2 \cdot 25$ \\
\hline Less than 40 & 46 & 8 \\
\hline
\end{tabular}


Schistosomiasis, which is endemic in this part of the Sudan, was another potent factor not to be overlooked. It is certainly responsible for secondary avitaminosis brought about by the resultant digestive disorder, debility, and anaemia in some of the cases. (Table II).

TABLE II

TOTAL NUMBER OF CASES EXAMINED, 515

\begin{tabular}{|c|c|c|c|c|c|c|}
\hline \multicolumn{5}{|c|}{ Type of Infection } & \multirow{2}{*}{$\frac{\text { Number of Cases }}{30}$} & \multirow{2}{*}{$\frac{\text { Percentage }}{6}$} \\
\hline Schisto & ma haematol & & .. & .. & & \\
\hline Schisto & ma mansoni & .. & .. & .. & 48 & 9 \\
\hline Mixed & .. & .. & .. & .. & 5 & 1 \\
\hline
\end{tabular}

Considering the results of these limited laboratory investigations, one cannot but attribute considerable importance to anaemia and schistosomiasis as conditioning factors, because it can hardly be a matter of chance that they should co-exist with severe manifestations of avitaminosis in practically every case examined.

\section{Summary}

(1) The results of a survey for ocular manifestations of vitamin deficiency in the Gezira-irrigated area, Blue Nile Province, are given.

(2) The series consisted of 1,265 patients. Of these 670 were seen in the central hospital of the area at Wad Medani and 595 at some villages inside the Gezira scheme.

(3) Typical signs and symptoms of multiple avitaminosis were discovered in 85 per cent. of the total number of cases examined.

(4) The commonest deficiency was that of vitamin $\mathrm{A}$ ( 56 per cent.), next that of the vitamin B-group (24.0 per cent.), and last that of the vitamin C (5 per cent.) (Table III).

TABLE III

TOTAL NUMBER OF CASES EXAMINED, 1,265

\begin{tabular}{lll|c|c}
\hline \multicolumn{2}{c|}{ Nature of Deficiency } & Number of Cases & Percentage \\
\hline Multiple vitamin deficiency & $\ldots$ & $\ldots$ & $\ldots$ & 1075 \\
\hline Vitamin A deficiency predominating & $\ldots$ & $\ldots$ & 709 & 86 \\
\hline Vitamin B-Group deficiency predominating & $\ldots$ & 304 & 56 \\
\hline Vitamin C deficiency predominating & $\ldots$ & $\ldots$ & 62 & 5 \\
\hline
\end{tabular}


(5) Vitamin D deficiency is not common here, and no case with ocular changes due to deficiency of vitamin $\mathrm{D}$ was discovered.

(6) The local disturbance of vitamin $A$ to the conjunctiva as a cause of non-deficiency xerotic conditions, such as trauma, trachoma, and ocular pemphigus is discussed.

(7) The relation of vitamin deficiencies to congenital anomalies and malformations is discussed.

My thanks are due to Dr. K. A. Ramadan, Province Medical Officer of Health, Gezira-irrigated Area, for his kind permission to allow this survey to be made in his area, to Dr. I. A. Hussien, Province Medical Officer of Health, Blue Nile Province, for his personal help and for provision of all facilities, including transport and laboratory and other equipment, and to Dr. N. A. Mageed, Physician to Wad Medani Civil Hospital, for his valuable work of elicitation and clinical evaluation of the general deficiency manifestations.

I am also indebted to Sayed A. E. Tigani, Senior Public Health Inspector, Gezira-irrigated Area, for the trouble he took in gathering data on the nutritional state of the villages surveyed and for taking an active part by measuring the weights and heights of all children.

To Sayed A. Dusuki, laboratory technician to Wad Medani Hospital, and to his colleagues my thanks are extended for their well-done estimations of haemoglobin and examinations of urine and stools in almost 600 cases.

Finally, I am grateful to the Headmaster, Headmistress, and Staff of the Village schools for willingly and whole-heartedly assisting in the organization and smooth running of the work.

\section{REFERENCES}

Adams, A. R. D., and Maegraith, B. G. (1953). “Clinical Tropical Diseases”, 1st ed. Blackwell, Oxford.

Adler, F. H. (1953). “Physiology of the Eye: Clinical Application”, 2nd ed., pp: 596-97. Mosby, St. Louis.

Davidson, L. S. P. (1956). "The Principles and Practice of Medicine", 3rd ed. Livingstone, Edinburgh.

Davson, H. (1949). "The Physiology of the Eye", pp. 60-61. Churchill, London.

DukE-ElDER, S. (1949). "Text-book of Ophthalmology", vol. 4, p. 4111. Kimpton, London. and Goldsmith, A. J. B. (1951). "Recent Advances in Ophthalmology", 4th ed., pp. 325-326. Churchill, London.

HAEssler, F. H. (1953). "Ophthalmologic Diagnosis", p. 147. Williams and Wilkins, Baltimore.

ManN, I. (1949). " "The Development of the Human Eye”, p. 275. British Medical Association, London.

Sheldon, W. (1955). "Diseases of Infancy and Childhood", 7th ed. Churchill, London.

SorSBY, A. (1948). "Modern Trends in Ophthalmology", vol. 2, pp. 192, 197. Butterworth, London.

(1951). "Systemic Ophthalmology", pp. 320, 675. Butterworth, London.

Town, A. E. (1951). "Ophthalmology", p. 443. Lea and Febiger, Philadelphia.

TREVOR-ROPER, P. D. (1955). "Ophthalmology", pp. 441, 628. Lloyd-Luke, London. 